idea (outlined in the first part of this review) of what it is all about, as can be required of anybody reporting on so difficult a theme.

Lastly, there are several pages of charts surveying the development of phenomenology in Germany and in France, followed by indexes and a glossary.

All this is a most valuable addition to the literature of the subject. One could make minor criticisms of style, like the irritating repetition of the phrase "to be sure" and the graceless abbreviation "photo". But these are trifles in an excellent treatment. Edmund Husserl remains at the centre of the stage, around him grouped both disciples and critics united, whatever their differences, to do him honour. F. I. G. RAwLINS

\section{MODERN STYLE IN MATHEMATICAL ANALYSIS}

Foundations of Modern Ana!ysis

By J. Dieudonné. (Pure and Applied Mathematics : a Series of Monographs and Textbooks, Vol. 10.) Pp. xiv +361 . (New York: Academic Press, Inc.; London: Academic Press, Inc. (London), Ltd., 1960.) 8.50 dollars.

$\mathrm{T}^{\mathrm{N}}$ recent decades tremendous changes have come about in many branches of pure mathematics. Not only have content and emphasis altered, but in addition there has been a fundamental change in the interpretation of large sections of classical mathematics. Abstraction and generalization, leading to the unification of previously scattered concepts, have played a powerful part in this process. One of the most vigorous protagonists of this activity has been the Bourbaki school of French mathematicians. The Bourbaki point of view on mathematical analysis is admirably presented in the book by Prof. $J$. Dieudonné. For every notion the concept itself is emphasized rather than the manipulation involved in using the notion, and this applies to the large number of problems as well as the text itself.

The book starts with an account of the theory of sets and the properties of real numbers and the real line. Then come two very important chapters, on metric spaces and normed spaces. The contents of these chapters form the backbone of the whole work, and are fundamental for all that follows. The important notions in a metric space are completeness, compactness and connectedness. These are carefully introduced, after a good deal of preliminary terminology, which deals essentially with geometrical ideas that remain unaltered under 'deformations'. For a normed space the fundamental results are the continuity criterion and a theorem of F. Riesz characterizing finite dimensional spaces, the latter being vital in spectral theory. The next two chapters deal with Hilbert spaces and with spaces of continuous functions, including the Stone-Weierstrass approximation theorem and some applications. It is at this stage that the reader comes to a presentation of the differential calculus. The theorems are familiar to all mathematicians, but are presented, against the background of the previously developed ideas, in a way which will be new to many readers. This formulation, involving greater abstraction and more mental effort, is considered worth while because it prepares the reader for the ideas of the calculus on a differentiable manifold. There follows a chapter on plane topology (the method of Eilenberg). Then analytic functions with an appendix on applications. A chapter on existence theorems presents results in the theory of differential equations, these results being linked with the notion of completeness. Finally, there is a chapter on spectral analysis, a subject chosen because it draws on all the material presented earlier in the book and leads to one of the main branches of functional analysis.

Apart from its actual mathematical content, the book is especially important because of the impact it will have on mathematical analysts, as to what should be taught to students of pure mathematics and how it should be presented. Prof. Dieudonné is particularly outspoken about several matters. For example, there is no mention of the theory of the 'Riemann integral', and the author states: "It may well be suspected that, had it not been for its prestigious name, this would have been dropped long ago, for (with due reverence to Riemann's genius) it is certainly quite clear to any working mathematician that nowadays such a 'theory' has at best the importance of a mildly interesting exercise in the general theory of measure and integration. Only the stubborn conservatism of academic tradition could freeze it into a regular part of the curriculum, long after it had outlived its historical importance". For another example, it may be noted that in the chapter on analytic functions the common idea of a 'multiple-valued' function is not introduced, and reasons are given why this idea is limiting and undesirable.

It is important that the reader should understand the aim of this book as well as its contents. For it is a book that lives : it has orientation as well as content and the orientation is justified. At the present time, when there is considerable heart-searching as to what should constitute a curriculum in pure mathematics and how it should be presented, it is particularly fitting that this book should appear, for it may help to clear the way in a somewhat twisted jungle of ideas and prejudices. It may be helpful to quote a part of Prof. Dieudonnés introduction :

"My opinion is that the graduate student of to-day must, as soon as possible, get a thorough training in this abstract and axiomatic way of thinking, if he is ever to understand what is currently going on in mathematical research. This volume aims to help the student to build up this 'intuition of the abstract' which is so essential in the mind of a modern mathe. matician.

"It is clear that students must have a good working knowledge of classical analysis before approaching this course." L. S. GodDARD

\section{AGE AND KINSHIP IN AUSTRALIA}

\section{Classification of Kin, Age Structure, and Marriage} amongst the Groote Eylandt Aborigines

A Study in Method and a Theory of Australian Kinship. By Frederick G. G. Rose. (Deutsche Akademie der Wissenschaften zu Berlin. Völkerkundliche Forschungen, Band 3.) Pp. xii +572. (397 Abbildungen.) (Berlin: Akademie-Verlag; London: Pergamon Press, 1960.) 100s. net.

THIS book concentrates on two highly important matters in the analysis of descent systems: the significance of relative age, and the factual documentation of the constitution and working of particular systems. The society dealt with is the 